\title{
Open access renewable resources, urban unemployment, and the resolution of dual institutional failures
}

\author{
Ichiroh Daitoh, ${ }^{1 \star(D)}$ and Nori Tarui ${ }^{2}$ \\ ${ }^{1}$ Faculty of Business and Commerce, Keio University, Tokyo, Japan and ${ }^{2}$ Department of Economics, \\ University of Hawaici at Mānoa, Honolulu, HI, USA \\ ${ }^{*}$ Corresponding author. E-mail: idaitoh@fbc.keio.ac.jp
}

(Submitted 25 January 2020; revised 03 November 2020, 16 June 2021; accepted 28 August 2021; first published online 16 November 2021)

\begin{abstract}
This paper investigates how poverty reduction and natural resource preservation can be simultaneously achieved in a small open dual economy with urban wage rigidity, open access rural resources, and rural-urban migration. An increase in the export tax rate on the rural resource good increases urban unemployment in both the short run and the long run with resource dynamics. Given the institutional failures, the first-best policy is an urban wage subsidy combined with either a rural wage subsidy at a lower rate or, if the urban output price is sufficiently high, a rural tax. When the institutional failures can be resolved endogenously, an increase in the export tax on the resource good can induce rural institutional change away from open access. However, tariff protection of urban manufacturing hinders such a rural institutional change.
\end{abstract}

Keywords: export tax on the resource good; institutional change; open access; renewable resource; ruralurban migration; urban unemployment

JEL Classification Codes: O13; Q27; F18

\section{Introduction}

Poverty reduction and environmental preservation are fundamental challenges for many developing economies. The economics literature has explored policies to address these dual goals by applying the traditional dual economy model in Harris and Todaro (1970). ${ }^{1}$

\footnotetext{
${ }^{1}$ See Wang (1990), Daitoh (2003, 2008), Beladi and Chao (2006), Rapanos (2007), Tsakiris et al. (2008), Daitoh and Omote (2011). The Harris Todaro model, despite its simplicity, is still used in the current research on urban unemployment in a dual developing economy because there are no other rural-urban models that can explain urban unemployment as an equilibrium phenomenon. The spatial economics literature on endogenous rural-urban configuration does not consider urban unemployment in equilibrium.
} 
These studies, with few exceptions, have focused on simultaneous reductions in urban industrial pollution and urban unemployment due to the institutionally-fixed high wage rate and rural-urban migration.

However, rural environmental resources also play important economic and environmental roles in low-income economies. The majority of low-income countries are highly dependent on primary product exports, while their natural resource dependency is associated with poor economic performance (stylized facts in Barbier, 2005). The compatibility of rural resource preservation and the resolution of urban problems, including unemployment, has attracted keen interest from policymakers. Some previous studies have discussed the association between land-use dynamics and rural-urban migration in the current developing world (e.g., Aide and Grau (2004) for Latin American countries). Other studies indicate the linkages between, on the one hand, rural outmigration resulting from drought and environmental degradation and, on the other hand, the urban poverty and health issues faced by urban migrants (Simms and Reid, 2006: 39). ${ }^{2}$ Izquierdo et al. (2011) found that under the future land-use/cover scenarios they considered, rural-to-urban migration and land-use planning could enhance forest conservation with little impact on urban areas in Argentina. These studies indicate that continued rural-to-urban migration may reduce pressures on rural resource use without aggravating urban poverty.

This paper considers whether rural resource preservation could be compatible with urban poverty reduction, in general, in a dual economy. For this purpose, we extend a small open Harris-Todaro (HT hereafter) model by incorporating renewable resource dynamics into the rural sector: while discouraging rural resource exploitation (or encouraging urban manufacturing) mitigates resource overuse, the accompanying ruralto-urban migration may increase urban unemployment. Empirical studies have found that the poor economic performance of resource-dependent economies is the outcome of the pervasiveness of poorly-defined property rights on natural resources (Barbier, 2005; Fischer, 2010; Barma et al., 2012). In fact, imperfect rural institutions that lead to natural resource overuse and urban institutional failure that induces persistent urban unemployment and poverty in informal sectors pose key challenges for many developing countries. Thus, we investigate whether and how rural resource preservation and a reduction in urban unemployment could be compatible in a small open dual economy with an institutionally-fixed high urban wage and open access rural resources. We assume open access because it can clearly show interactions of rural and urban institutional failures. ${ }^{3}$

This study applies the following three analyses. First, we investigate the effect of an increase in the export tax rate on the rural resource good because it is one of the most common policy instruments imposed on natural resource sectors in developing countries (WTO, 2010). ${ }^{4}$ Abe and Saito (2016) found that the higher export tax rate

\footnotetext{
${ }^{2}$ Grau and Aide (2008) note that in recent decades, forest expansion or the recovery of degraded forests has been reported for several Caribbean and Central American areas in association with the strong impact of rural outmigration and economic modernization.

${ }^{3}$ According to Barbier (2005: 122), studies in the literature document the rent-dissipation effect of poorlydefined property rights regimes, including the breakdown of traditional common property right regimes, in developing countries. Open access captures the essence of such rent-dissipation effects.

${ }^{4}$ The World Trade Organization (WTO) (2010: 116) notes that while natural resources represent less than one-quarter of all tradable sectors, fully one-third of all export taxes recorded in the WTO's Trade Policy Reviews are imposed on natural resource sectors. The WTO (2010, figure 28) also finds that export
} 
always reduces resource overuse but increases the rate of urban unemployment in the short run when the resource stock level is fixed. We confirm this incompatibility result in a more general setting with resource dynamics. In our model, an increase in the export tax rate may either improve or deteriorate welfare because the associated reduction in rural population and rise in the steady-state resource stock may increase or decrease the rural output and thus the aggregate income. With this finding, we could assess some Southeast Asian countries' changes in their timber export regulations since the 1970 s.

Second, we find that the first-best policy, which attains efficient labor allocation, is an urban wage subsidy combined with a rural wage subsidy at a lower rate. This recommendation requires a modification of the traditional first-best policy proposed by Bhagwati and Srinivasan (1974), i.e., a combination of urban and rural wage subsidies at the same rate. In particular, a rural tax (instead of a subsidy) will be the first-best rural policy when: (a) the urban fixed wage rate is lower, (b) the domestic relative price of the urban manufactured good is higher (e.g., a lower world relative price of the resource good under free trade and/or a higher tariff rate on the manufactured good), (c) the productivity of rural technology is higher, or (d) the rural resource's carrying capacity is larger. Although we assume that the urban wage rate is institutionally fixed, generalizing our model by endogenizing the urban wage rate and by formally modeling the urban informal sector does not change our main results about the nature of the first-best policy and the impacts of export taxes.

Third, we explore conditions under which the trade policies commonly observed among developing countries with natural resources endogenously induce institutional change. We find that an increase in the export tax rate on the rural good will enhance the incentive for rural institutional change from open access if the relative share of labor in the rural resource good sector is sufficiently large or if the resulting rate of increase in the urban unemployment rate is sufficiently high. Tariff protection on urban manufacturing necessarily reduces the incentive for rural institutional change, maintaining open access. We also investigate how institutional failure in the urban labor market may be endogenously resolved by these trade policies.

Previous studies have addressed the economic consequences of rural and urban institutional failures by applying two-sector models. One strand of literature investigates the effect of incomplete property rights over environmental resources on the gains from trade, but by assuming no distortions in the urban labor market (e.g., Chichilnisky, 1994; Brander and Taylor, 1997, 1998). Another group of studies illustrates how trade policies affect the welfare of a small open economy in the presence of urban fixed high wage but assumes perfectly enforced private ownership of rural resources (e.g., Dean and Gangopadhyay, 1997; Chao et al., 2000). Noack et al. (2018) apply a dynamic model of a dual economy to consider the income differences between a rural sector with an open access renewable resource and an urban sector given costly migration, but do not consider urban unemployment. This paper builds on these studies by incorporating both rural and urban institutional failures to illustrate the welfare consequence of various trade policies in the presence of urban unemployment.

taxes occur with greater frequency in the fishing and forestry (renewables) industries than in the fuels and mining (non-renewables) industries. 


\section{The model}

\subsection{Small open dual economy with open access rural resources in the steady state}

Consider a small open dual economy with a rural sector producing a resource good $R$ (the world price $\bar{q}$ is normalized to be equal to 1 ) and an urban sector producing a manufactured good $M$. Under free trade, the domestic price $p$ of good $M$ is equal to its world price, $\bar{p}>0$. We assume that the urban wage rate $w_{M}>0$ is institutionally fixed at the level exceeding any prevailing market clearing level. The microeconomic foundations for high urban wages have been explained through bargaining with labor union, the efficiency wage hypothesis and labor turnover models in the development economics literature (Todaro and Smith, 2015: 361-362; de Janvry and Sadoulet, 2016: 443). By simply assuming that $w_{M}$ is fixed by the minimum wage law, we zero in on our main question of interest, i.e., how the institutional failure of the urban labor market may interact with rural institutional failure. In what follows, we consider an equilibrium with urban unemployment where good $R$ is exported and good $M$ is imported.

We assume that the resource good (harvest) $R \geq 0$ is produced with rural labor $L_{R} \geq 0$ and a renewable resource stock $S \geq 0$ under the Schaefer production function:

$$
R=\alpha S L_{R}
$$

where $\alpha>0$ represents the productivity of resource good production. As a rural institutional failure, we assume that the resource is subject to open access. Because rural agents can freely use $S$ to produce $R$ using their own labor, rural income per capita $w>0$ satisfies the zero-rent condition $R=w L_{R}$ in equilibrium; hence,

$$
w=\alpha S \text {. }
$$

At any point in time $t$, the resource stock $S_{t}$ increases according to $\dot{S}_{t} \equiv d S_{t} / d t=$ $G\left(S_{t}\right)-R_{t}$ (a dot represents a time derivative). We assume that the logistic growth function of the renewable resource is $G(S)=r S(1-(S / K))$, where $r>0$ is the intrinsic growth rate of the resource and $K>0$ is its carrying capacity. In the steady state where $S_{t}=0$, we have:

$$
r S\left(1-\frac{S}{K}\right)=R .
$$

Equations (1) and (3) imply the following relationship between the steady-state resource stock level and the associated labor input:

$$
S\left(L_{R}\right)= \begin{cases}K\left(1-\frac{\alpha}{r} L_{R}\right) & \text { if } 0 \leq L_{R} \leq \frac{r}{\alpha} \\ 0 & \text { if } L_{R}>\frac{r}{\alpha}\end{cases}
$$

The associated output level, which is called the 'sustainable yield' in resource economics, satisfies $R\left(L_{R}\right)=\alpha S\left(L_{R}\right) L_{R}$. Our main focus is the steady state of the resource stock because the effect on the transition path will turn out to be dominated by the effect on the steady state.

The urban manufacturing production function $F\left(L_{M}\right)$ has a positive and decreasing marginal product of labor $\left(F^{\prime}\left(L_{M}\right)>0, F^{\prime \prime}\left(L_{M}\right)<0\right)$ and satisfies the Inada conditions $\left(\lim _{L_{M} \rightarrow 0} F^{\prime}\left(L_{M}\right)=\infty, \lim _{L_{M} \rightarrow \infty} F^{\prime}\left(L_{M}\right)=0\right)$, where $L_{M} \geq 0$ is the manufacturing employment. A competitive urban manufacturing firm maximizes its profit $p F\left(L_{M}\right)-$ 
$w_{M} L_{M}$ by employing $L_{M}$ at the level where the value of the marginal product of urban manufacturing labor in terms of domestic price $p$ equals the institutionally-fixed urban wage rate:

$$
w_{M}=p F^{\prime}\left(L_{M}\right)
$$

As in the standard HT model, rural-urban migration ceases when the expected wage or income levels are equalized between rural and urban areas:

$$
w=\frac{w_{M} L_{M}}{L_{M}+L_{U}}=\frac{w_{M}}{1+\mu},
$$

where $\mu \equiv L_{U} / L_{M} \geq 0$ and $L_{U} \geq 0$ are the rate and level of urban unemployment. ${ }^{5}$ Given total population $L>0$, the allocation of rural labor, urban manufacturing employment and urban unemployment is determined at each point in time:

$$
L_{R}+(1+\mu) L_{M}=L
$$

Given $p, w_{M}$ and $L$, equations (1), (2), (3), (5), (6) and (7) determine the steadystate equilibrium values of six endogenous variables $R, S, w, L_{R}, L_{M}$, and $\mu .{ }^{6}$ As in the neoclassical trade model, this equilibrium on the production side is determined independently of the consumption side in our model. Thus, we will first analyze the production equilibrium and then incorporate the demand for goods under homothetic utility, investigating welfare. Then, other things being equal, a higher level of the aggregate income, which is equal to the gross domestic product (GDP), leads to higher welfare.

\subsection{Properties of an HT equilibrium with open access rural resources}

We will explain three distortions due to the dual institutional failures by analytically solving the HT equilibrium. First, given the fixed high wage rate $w_{M}$, the urban manufacturing employment $L_{M}^{*}=L_{M}\left(w_{M} / p\right)$ predetermined by (5) is less than the employment in a competitive urban labor market. The second distortion is urban unemployment. We can obtain its equilibrium rate $\mu^{*}=\left(L_{U}^{*} / L_{M}^{*}\right)$ by simultaneously solving $\lambda \alpha S\left(L_{R}\right)=w_{M}$ and $L_{R}+\lambda L_{M}^{*}=L$ derived from (2), (4), (6) and (7) for $\left(L_{R}^{*}, \lambda^{*}\right)$, where $\lambda=1+\mu$ is the gross urban unemployment rate. The third distortion is rural resource overuse due to open access. The 'resource overuse' in this paper means larger usage of resource stock under open access than that by profit maximizing firms under a perfect property rights system, which comes from a higher average product of rural labor $w=\alpha S\left(L_{R}\right)$ than its marginal product $R^{\prime}\left(L_{R}\right)$.

The analytical explanations above do not seem sufficiently clear because the less-thanoptimal manufacturing employment $L_{M}^{*}$ and the urban unemployment $L_{U}^{*}$ are mixed in $\mu^{*}$ and because the relations among these distortions are not explicitly shown. We can make much clearer explanations for them by using the standard graphical analysis by Corden and Findlay (1975). In figure $1, L_{M}^{*}$ is shown by $O_{M} J$, with origin $O_{M}$. Given $w_{M}$

\footnotetext{
${ }^{5}$ In the HT framework, the unemployment rate is defined as the ratio $\mu$ of the number $L_{U}$ of urban unemployed people to the number $L_{M}$ of urban manufacturing workers. This ratio always moves in the same direction as the standard urban unemployment rate, $L_{U} /\left(L_{M}+L_{U}\right)=1 /\{1+(1 / \mu)\}$.

${ }^{6}$ Section 2.2 explains the existence of a unique interior general equilibrium solution under mild conditions, i.e., under assumption 1 (presented later). The online appendix provides more rigorous proof.
} 


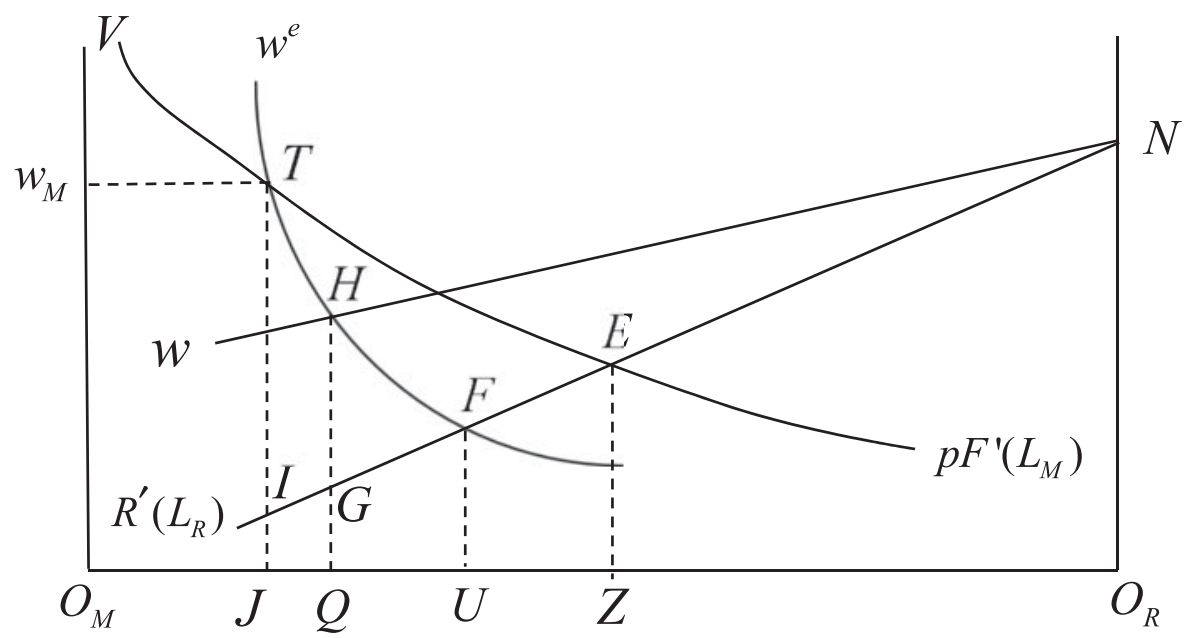

Figure 1. Harris-Todaro equilibrium with open access rural resources.

and $L_{M}^{*}$, the expected urban wage rate $w^{\mathrm{e}}=w_{M} L_{M}^{*} / L_{C}$ can be regarded as a decreasing function of the city population $L_{C}\left(=L_{M}^{*}+L_{U}\right)$, measured from origin $O_{M}$ to the right. This rectangular hyperbola $w^{e}$ passing through point $T$ (because $w^{e}=w_{M}$ holds at $L_{C}=L_{M}^{*}$ ) is called the Harris-Todaro (HT) curve. The HT curve intersects with the rural income line $w=\alpha S\left(L_{R}\right)$, which originates at $O_{R}$, at point $H$ called the HT equilibrium, where the city and rural populations are $O_{M} Q$ and $O_{R} Q$, respectively. The level of urban unemployment $\mu L_{M}^{*}$ is shown by JQ. In our HT equilibrium, $w^{*}=\alpha S\left(L_{R}^{*}\right)$ is always positive, and thus, $1>(\alpha / r) L_{R}^{*}$ holds. ${ }^{7}$ Under

Assumption 1: $w_{M}\left(L_{M}\left(w_{M} / p\right) / L\right)<\alpha K$, the equilibrium labor allocation is an interior solution because the height of point $N(=\alpha K)$ exceeds the expected urban wage rate $w^{\mathrm{e}}$ at $L_{C}=L$, i.e., when the total population lives in the urban area.

We can elucidate the relations among three distortions in terms of losses in GDP. As a benchmark for policy evaluation given the dual institutional failures, we focus on the efficient labor allocation that maximizes GDP, which we call the 'first-best labor allocation'. At the first-best labor allocation point $E$, where the value of marginal product $p F^{\prime}\left(L_{M}\right)$ is equal to the value of marginal product $R^{\prime}\left(L_{R}\right)$, GDP is shown by $O_{M} V E N O_{R}$.

The two distortions due to the fixed high wage rate $w_{M}$ induce GDP losses as follows. First, the manufacturing employment $\left(O_{M} J\right)$ is below the first-best level $O_{M} Z$. The value of urban manufacturing production is $O_{M} V T J$, and thus the corresponding GDP loss would be EZJT. If the remaining population $\left(O_{R} J\right)$ lived in the rural area, then rural production would increase by EZJI, and thus the net GDP loss would be EIT. However, people tend to migrate to an area where the expected wage/income is higher. Without open access to the resource stock, the rural population would be represented by the intersection $F$ of the rural marginal product curve $R^{\prime}\left(L_{R}\right)$ and the $H T$ curve. Population $J U$ would move from the rural to the urban areas, resulting in urban unemployment (of the

\footnotetext{
${ }^{7}$ When $R^{\prime}\left(L_{R}^{*}\right)<0$ holds at the equilibrium point $H$, the rural population is larger than the level corresponding to the 'maximum sustainable yield' at which reproduction is maximal, i.e., $G(S)$ is maximized.
} 
same size, $J U$ ). Thus, the value of rural production would decrease by FUJI. This process is the second reason for GDP loss.

The third distortion due to the second institutional failure - which is specific to our HT model - is excess rural production due to open access; the rural population $O_{R} Q$ is determined by the average product $w=\alpha S\left(L_{R}\right)$ at point $H$, which is larger than $O_{R} U$ determined by the marginal product $R^{\prime}\left(L_{R}\right)$ at point $F$. Then, the level of urban unemployment $(J Q)$ is less than the length of $J U$, which increases the value of rural production by FUQG (the value of rural production is $O_{R} N G Q$ ). Hence, rural resource overuse tends to reduce urban unemployment. Taking these effects together, the overall GDP loss is shown by EGQJT.

\section{Export tax on the resource good}

In this section, we investigate the effects of an increase in the ad-valorem export tax rate $\tau$ on the resource good. ${ }^{8}$ The value of the resource good in terms of its domestic price $q=\bar{q} /(1+\tau)$ is $R^{\tau}=R /(1+\tau)$. Each rural producer's income (2) is replaced with (2'), $w^{\tau}=\alpha S /(1+\tau)$, and (6) with (6'), $w^{\tau}=w_{M} /(1+\mu)$. We first derive the effects on resource use and urban unemployment. Then, assuming homothetic utility, we investigate GDP and welfare impacts in the steady state, taking into account the effects on the transition path.

The steady-state comparative-static results are obtained by totally differentiating $\lambda \alpha S\left(L_{R}\right)=(1+\tau) w_{M}$ and $L_{R}+\lambda L_{M}^{*}=L$ with $d w_{M}=d L_{M}=d L=0$ and solving for $\left(d L_{R}, d \lambda\right):$

$$
\frac{d L_{R}^{*}}{d \tau}=-\frac{w_{M} L_{M}^{*}}{\alpha S\left(L_{R}\right)-\lambda \alpha S^{\prime}\left(L_{R}\right) L_{M}^{*}}<0, \quad \frac{d \mu^{*}}{d \tau}=\frac{d \lambda^{*}}{d \tau}=\frac{w_{M}}{\alpha S\left(L_{R}\right)-\lambda \alpha S^{\prime}\left(L_{R}\right) L_{M}^{*}}>0 .
$$

An increase in $\tau$ reduces rural population $L_{R}^{*}$, mitigating the resource overuse, but raises the urban unemployment rate $\mu^{*}$ (because $S^{\prime}\left(L_{R}\right)<0$ ). Hence, rural resource preservation contradicts urban poverty reduction in the steady state.

Suppose that all consumers' utility functions are the same and homothetic in the consumption of the resource good $c_{R}$ and the manufactured good $c_{M}$. Let $E(q, p, u)$ be the representative consumer's expenditure function, where $q=1 /(1+\tau)$ is the domestic price of good $R$ and $u$ is the utility level. The aggregate consumption expenditure is equal to the aggregate revenue in terms of the domestic price, i.e., $E(1 /(1+\tau), p, u)=(R /(1+\tau))+p M+(\tau /(1+\tau))\left[R-E_{q}(1 /(1+\tau), p, u)\right]$, where $E_{q}(1 /(1+\tau), p, u)=(\partial E / \partial q)=c_{R}$ is the domestic compensated demand for good $R .{ }^{9}$ The export tax revenue (the third term on the right-hand side) is assumed to be distributed to consumers in a lump-sum fashion. By totally differentiating this equation with $d p=d M=0$, we obtain:

$$
\left[E_{u}+\frac{\tau}{1+\tau} E_{q u}\right] \frac{d u}{d \tau}=\frac{d R}{d \tau}+\frac{\tau}{1+\tau} \frac{E_{q q}}{(1+\tau)^{2}} .
$$

Though the compensated demand is decreasing in its own price $\left(E_{q q}=\left(\partial^{2} E\right)\right.$ $\left.\partial q^{2}\right)<0$ ), the welfare may increase or decrease because rural output $R^{*}$ may or may not fall.

\footnotetext{
${ }^{8}$ We thank Kenzo Abe for his useful discussion on the analysis in this section.

${ }^{9}$ From this expression, we can derive $c_{R}+\bar{p} c_{M}=R+\bar{p} M$ in terms of the world price. We also have $E_{q u}>0$ because $E_{q}$ is linear in $u$ under homothetic utility function.
} 
We can intuitively explain the economic mechanism as follows. An increase in the export tax rate $\tau$ on the resource good lowers its domestic price $q^{*}$ and thus rural income $w^{\tau *} \cdot{ }^{10}$ The induced rural-to-urban migration decreases rural population $L_{R}^{*}$, while it increases urban population $L_{C}^{*}$, aggravating the unemployment level $L_{U}^{*}$ and its rate $\mu^{*}$ (because $L_{M}^{*}$ is unchanged) in the steady state, as in Abe and Saito (2016) where resource dynamics are not considered. In our model with resource dynamics, the reduction in rural population $L_{R}^{*}$ increases the steady-state resource stock $S\left(L_{R}^{*}\right)$. Thus, rural output $R^{*}=\alpha S\left(L_{R}^{*}\right) L_{R}^{*}$ and GDP $=R^{*}+\bar{p} M^{*}$ may either increase or decrease. ${ }^{11}$ Welfare tends to improve by an increase in GDP but may deteriorate due to the distortion (reduction) in the domestic price $q^{*}$.

By applying (8), we could assess some Southeast Asian countries' changes in their timber export regulations since the 1970s. According to Tachibana (2000), Indonesia, Malaysia and the Philippines began to restrict and tightened log exports from the late 1970 s to the beginning of the 1990s (along with the promotion measures for the timberprocessing industries) because they faced serious deforestation due to excessive timber harvests. This situation could be regarded as the one where rural population exceeds the level associated with the 'maximum sustainable yield (MSY)', i.e., $R^{\prime}\left(L_{R}^{*}\right)<0$ holds under free trade $(\tau=0)$. Then, because $\left(d R^{*} / d \tau\right)=R^{\prime}\left(L_{R}^{*}\right)\left(d L_{R}^{*} / d \tau\right)>0$, introducing an export tax would improve welfare and thus it would make sense for the governments to strengthen the export regulations.

Because a higher export tax rate $\tau$ decreases rural population $L_{R}^{*}$, the absolute value of $R^{\prime}\left(L_{R}^{*}\right)=\alpha K\left(1-(2 \alpha / r) L_{R}^{*}\right)<0$ decreases. If $\left(d R^{*} / d \tau\right)>0$ is dominated by the term with $E_{q q}<0$, a decrease in $\tau$ improves welfare. This is also the case when $R^{\prime}\left(L_{R}^{*}\right)>0$ and thus $\left(d R^{*} / d \tau\right)<0$ holds. In 1996, Malaysia restarted log exports after reducing the export tax on wood products. After the Asian economic crisis in 1997, Indonesia eliminated trade restrictions on timber and reduced the export tax rates on $\log$ and sawn wood products to 30 per cent in $1998 .{ }^{12}$ To the extent that $R^{\prime}\left(L_{R}^{*}\right)>0$ applied in these circumstances, these tax cuts would have been welfare-improving.

We can also find the effects at the initial instant and along the transition path, summarizing the results in proposition 1 (see the online appendix for the derivation).

Proposition 1. Suppose the economy is at the steady state. An increase in the export tax rate $\tau$ on the resource good has the following results: (i) a decrease in the rural population $L_{R}^{*}$, and an increase in the rate $\mu^{*}$ and level $L_{U}^{*}$ of urban unemployment, (ii) a decrease in rural income per capita $w^{*}$ at the initial instant, (iii) the effects on rural output $R^{*}, G D P$ and welfare are ambiguous, and (iv) though $L_{R}^{*}, \mu^{*}$ and $w^{*}$ move in the opposite direction along the transition path, the steady-state effect is in the same direction as the initial effect.

Proposition 1 implies that rural resource preservation by an export tax, in general, contradicts urban poverty reduction in the steady state of a dual developing economy. The claim of Izquierdo et al.'s (2011) simulation results that rural-to-urban migration could enhance forest conservation with little impact on urban areas in Argentina does not seem to apply to developing economies in general. An interesting implication regarding result (iii) would be that, even in a resource-dependent dual economy where

\footnotetext{
${ }^{10}$ It implies that the export tax aggravates income inequality between rural and urban areas.

${ }^{11} R^{\prime}\left(L_{R}^{*}\right)=\alpha\left[S^{\prime}\left(L_{R}^{*}\right) L_{R}^{*}+S\left(L_{R}^{*}\right)\right]=\alpha K\left(1-(2 \alpha / r) L_{R}^{*}\right)$ can be positive or negative.

${ }^{12}$ Tachibana (2000) mentions that a reason behind these actions was that the governments depended on timber-related revenues, especially from export log royalty.
} 
rural population is larger than the level associated with the MSY, a decrease in export tax on the rural resource good may improve welfare because of a reduction in urban unemployment.

The rest of the paper focuses on the results for the steady state.

\section{First-best policy}

In this section, we will explore how we can simultaneously attain rural resource preservation and a reduction in urban unemployment in a dual economy. Following the traditional policy analysis in the HT models, we focus on the 'first-best policy (package)' which leads to the efficient labor allocation maximizing GDP given the institutional failures. ${ }^{13}$ We find that the first-best policy is a combination of an urban wage subsidy and a rural income subsidy at a lower rate or even a tax. This modifies the policy prescription by Bhagwati and Srinivasan (1974), i.e., a combination of rural and urban wage subsidies at the same rate. We assume that the government keeps its budget constraint by lumpsum transfers to consumers (all of them are employed under the first-best policy) when the rural income tax revenue differs from the urban wage subsidy payment. ${ }^{14}$

In our HT model with open access rural resource, the efficient labor allocation requires not only correcting rural resource overuse but also allocating labor between rural and urban areas so as to eliminate urban unemployment. While taxing rural production may be justified because open access leads to resource overuse, a subsidy to rural producers may be useful for limiting excessive rural-to-urban migration.

The government will use urban and rural wage subsidies $\left(s_{M}, s_{R}\right)$ (taxes if negative) as policy instruments for attaining the first-best labor allocation because they directly correct the distortions concerning urban and rural labor inputs. Under the wage subsidies, (2) and (5) will be $w-s_{R}=\alpha S\left(L_{R}\right)$ and $w_{M}-s_{M}=p F^{\prime}\left(L_{M}\right)$, respectively. Thus, the urban employment $L_{M}^{*}$ is predetermined by the urban wage subsidy $s_{M}$ independently of the rural income subsidy $s_{R}$. Needless to say, urban unemployment should be zero $(\mu=0)$ for the GDP to be maximized. The government chooses a combination of $\left(s_{M}, s_{R}\right)$ that maximizes GDP, $G=R\left(L_{R}\right)+p F\left(L_{M}\right)$, in the steady state subject to the full-employment condition $L_{R}+L_{M}=L$.

Defining the Lagrangian as $\tilde{L}=R\left(L_{R}\right)+p F\left(L_{M}\right)+m\left\{L-L_{R}-L_{M}\right\}$, we have:

$$
\begin{aligned}
\frac{\partial \tilde{L}}{\partial s_{M}} & =\left[R^{\prime}\left(L_{R}\right)-m\right] \frac{\partial L_{R}}{\partial s_{M}}+\left[p F^{\prime}\left(L_{M}\right)-m\right] \frac{\partial L_{M}}{\partial s_{M}}=0, \\
\frac{\partial \tilde{L}}{\partial s_{R}} & =\left[R^{\prime}\left(L_{R}\right)-m\right] \frac{\partial L_{R}}{\partial s_{R}}=0,
\end{aligned}
$$

\footnotetext{
${ }^{13}$ The most fundamental policy would resolve the dual institutional failures directly. However, the resolution of open access may require high costs of establishing a property rights system while the elimination of the fixed high wage may be infeasible for political reasons. Here we assume that eliminating the institutional failures is costly as in Copeland and Taylor (2009) and thus the direct resolution of institutional failures may not always be the first best. In section 5 , we consider the possibility of endogenous institutional change.

${ }^{14}$ Because the tax and subsidy rates are chosen so as to attain the first-best point, the rural tax revenue is not always equal to the urban subsidy payment. In figure 3 presented later, given $R^{\prime}\left(L_{R}\right)$ and $p F^{\prime}\left(L_{M}\right)$, the lower $w_{M}$ is, the more likely it is that the rural income tax revenue exceeds the urban wage subsidy payment.
} 


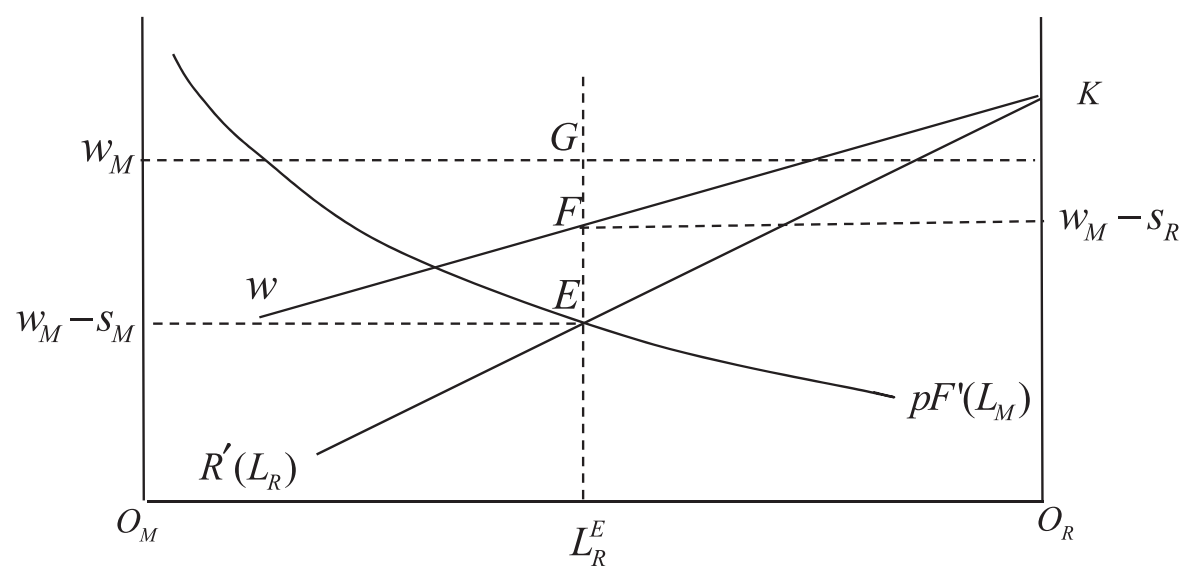

Figure 2. Rural income subsidy.

where $m$ is the Lagrange multiplier. From $R^{\prime}\left(L_{R}\right)=m$ and $p F^{\prime}\left(L_{M}\right)=m$, the efficient labor allocation $\left(L_{R}^{E}, L_{M}^{E}\right)$ is characterized by

$$
p F^{\prime}\left(L_{M}^{E}\right)=\alpha K\left(1-\frac{2 \alpha}{r} L_{R}^{E}\right) .
$$

The value of the marginal product of urban labor $p F^{\prime}\left(L_{M}\right)$ must be equal to that of rural labor associated with sustainable harvest $R^{\prime}\left(L_{R}\right)=\alpha S\left(L_{R}\right)+\alpha S^{\prime}\left(L_{R}\right) L_{R}=$ $\alpha K\left(1-(2 \alpha / r) L_{R}\right)$, where $S^{\prime}\left(L_{R}\right)=-\alpha K / r<0 .{ }^{15}$ Therefore, the optimal wage subsidies are $s_{M}=w_{M}-p F^{\prime}\left(L_{M}^{E}\right)$ and $s_{R}=w_{M}-\alpha S\left(L_{R}^{E}\right)$ because (6) implies $w=w_{M}$ under $\mu=0$. Note that $s_{R}$ can be positive or negative while $s_{M}$ is always positive.

In what follows, we assume:

Assumption 2. $p F^{\prime}(L)<\alpha K$.

This inequality means that the average product $(\alpha K)$ of rural labor at $L_{R}=0$ exceeds the value of marginal product $p F^{\prime}\left(L_{M}\right)$ when the total population works in urban manufacturing $\left(L_{M}=L\right)$. Figure 2 shows that the first-best labor allocation $E$ exists as an interior solution under assumption 2 and the Inada condition on $F$.

\subsection{First-best subsidies in a diagram}

Let us use diagrams to examine when the first-best urban and rural policies are a subsidy or a tax. In figure 2, the government provides each urban firm with the wage subsidy $s_{M}=E G$. Then, the manufacturing firms employ all the available workers $O_{M} L_{R}^{E}$ in the urban sector and each urban worker receives the urban fixed wage rate $w_{M}$. If the remaining $O_{R} L_{R}^{E}$ people work under zero rent in the rural sector, the rural income per capita $w=\alpha S\left(L_{R}\right)$, which is the (sustainable) average product of rural labor (the height of point $F$ ), is lower than the urban wage $w_{M}$. To eliminate the incentive for rural-to-urban

\footnotetext{
${ }^{15}$ The online appendix shows that this efficient labor allocation in our 'sustainable yield' model corresponds to the solution of the associated dynamic optimization problem with the discount rate close to zero. If the discount rate were larger, we could apply the analysis below by choosing associated subsidy/tax rates that support dynamically-efficient resource allocation.
} 


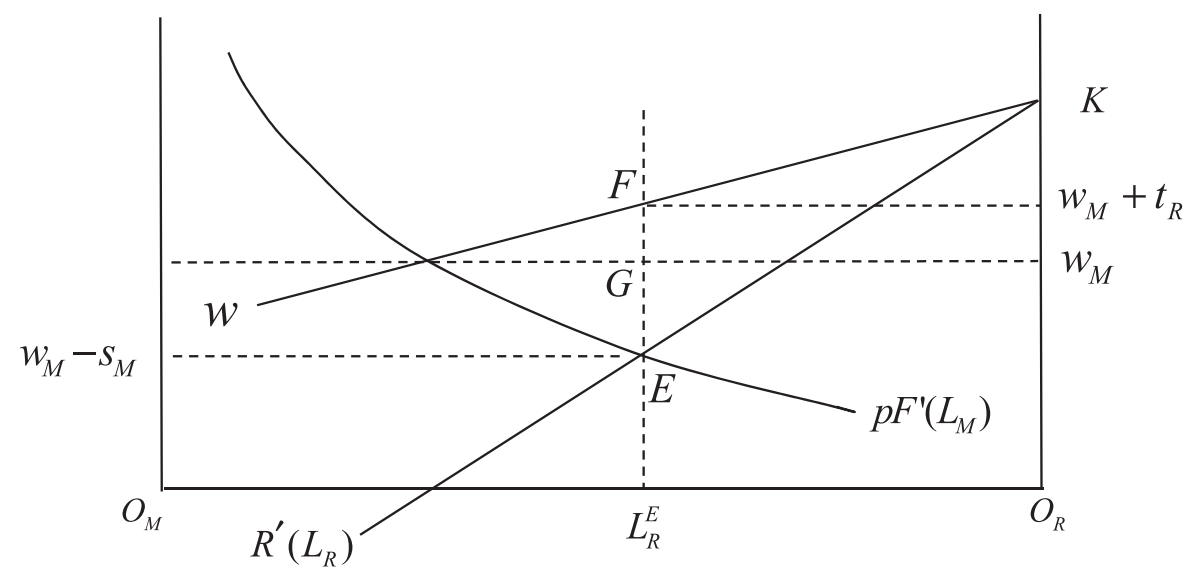

Figure 3. Rural income tax.

migration, the government could provide each rural producer with a subsidy $s_{R}=G F$. Therefore, the first-best policy is the combination of an urban wage subsidy $s_{M}=E G$ and a rural income subsidy $s_{R}=G F$.

\subsection{When is the rural policy a tax?}

The first-best rural policy can be a tax on rural income. In figure 3, the rural income $w$ under zero rent at the efficient rural labor $O_{R} L_{R}^{E}$ exceeds the urban wage $w_{M}$. The rural policy is a tax, $t_{R}=F G$, on each rural producer to eliminate the incentive for urban-torural migration.

We obtain the necessary and sufficient condition for a tax by the inequality $w_{M}<$ $w$ at $L_{R}^{E}$ :

$$
s_{R}=w_{M}-\alpha K\left(1-\frac{\alpha}{r} L_{R}^{E}\right)<0 .
$$

When: (i) $w_{M}$ is lower, (ii) $p$ is higher, (iii) $\alpha$ is higher, or (iv) $K$ is larger, (10) is more likely to hold (see the online appendix for rigorous analyses). The reason for (i) is that the tax rate required to correct resource overuse would exceed the subsidy rate necessary to address smaller urban labor market distortions due to the lower $w_{M}$. The reason for (ii) is that a higher $p$, which induces a higher $p F^{\prime}\left(L_{M}\right)$ curve, makes the firstbest rural population $O_{R} L_{R}^{E}$ smaller. Because of the diminishing returns to rural labor, the rural income $w$ tends to be higher than the fixed urban wage. To eliminate the incentive for urban-to-rural migration, the government could impose a tax $t_{R}=F G$ on the rural producers to ensure that their disposable income is equal to $w_{M}$. The reason for (iii) and (iv) is that, in these cases, the sustainable yield of the resource good is larger, and thus the rural distortion due to open access is relatively more significant. A rural tax correcting the resource overuse tends to be justified.

Proposition 2. (i) The first-best policy is a combination of an urban wage subsidy $s_{M}$ and a rural income subsidy $s_{R}$ at a lower rate or even a tax $t_{R}$. (ii) A rural income tax $t_{R}$ combined with an urban wage subsidy $s_{M}$ constitutes the first-best policy if and only if (10) 
holds. Thus, the first-best rural policy is more likely to be a tax when (a) the institutionallyfixed urban wage rate $w_{M}$ is lower; (b) the domestic price pof the urban manufactured good is higher; (c) the productivity of rural technology $\alpha$ is higher; or (d) the rural resource's carrying capacity $\mathrm{K}$ is higher.

Proposition 2 requires a modification of the traditional first-best policy proposed by Bhagwati and Srinivasan (1974), i.e., a combination of urban and rural wage subsidies at the same rate. Their policy package makes efficiency and equity compatible because urban and rural producers receive the same wage subsidies. In contrast, result (i) implies that the first-best policy for economies with rural institutional failures, as it is the case with many low-income countries (Barbier, 2005), favors urban firms with a wage subsidy but harms rural producers with a tax burden. Governments in those countries should create a more sophisticated policy package, taking this trade-off between efficiency and rural-urban equity into account. ${ }^{16}$

In particular, from (iib), the first-best policy is more likely to be a rural income tax with an urban wage subsidy when the world relative price $1 / \bar{p}$ of the resource good is lower under free trade and/or when a higher import tariff is imposed on the urban manufactured good (which leads to a higher domestic price $p$ ). In the latter case relevant for typical developing countries, urban firms are protected by the tariff while rural producers must pay the income tax. This further aggravates domestic income inequality between rural and urban producers.

\section{Resolution of institutional failures}

We have thus far considered the effects of policies on labor allocation given rural and urban institutional failures. Following recent studies focusing on endogenous institutional change (Bulte and Barbier, 2005; Copeland, 2005; Copeland and Taylor, 2009; Margolis and Shogren, 2009; Fischer, 2010), we explore whether and when these institutional failures could be resolved by an export tax $\tau$ on the rural resource good and an import tariff $t$ on the urban manufactured good, which are observed in many developing countries with natural resources. We consider the export tax because institutional change may occur if the rural resource rent under restricted access is sufficiently large (de Meza and Gould, 1992; Margolis and Shogren, 2009). The import tariff could make the institutionally-fixed urban wage rate flexible (i.e., endogenously determined) by increasing the demand for urban labor.

Following the 'threshold model' of institutional change (e.g., Copeland, 2005: 10), we analyze the incentive for institutional changes by examining whether the maximum sustainable rent, which is equal to the profit of competitive firms producing the resource good in the steady state, exceeds the cost of enforcing resource management, $C>0$. If the maximum sustainable rent increases given the $\operatorname{cost} C$, then the trade policies will induce institutional change.

\subsection{Institutional changes under an export tax on the rural resource good}

First, we investigate how an increase in the export tax rate would influence rural institutional change. Consider the hypothetical situation in which the rural firms that own the

\footnotetext{
${ }^{16}$ If the rural good was used as inputs in the urban sector, this trade-off would be less severe than in the present model where it is directly exported without being processed in the urban manufacturing.
} 
resource stock choose their labor input to maximize profit $\pi\left(L_{R}\right)=\left(R\left(L_{R}\right) /(1+\tau)\right)-$ $w_{R} L_{R}$. The online appendix shows that the maximum sustainable rent increases if and only if:

$$
\frac{R\left(L_{R}^{*}\right)}{w_{R} L_{R}}<(1+\tau)^{2} \frac{d \lambda^{*} / d \tau}{\lambda^{*}} .
$$

In contrast, an export tax on the rural resource good does not affect the incentive to resolve urban institutional failure because it has no effects on the equilibrium urban manufacturing employment. This establishes the next proposition.

Proposition 3. (i) An increase in the export tax rate on the rural resource good may or may not enhance the incentive for rural institutional change away from open access to a perfect private property system. The necessary and sufficient condition for increasing this incentive is that (11) holds at the initial equilibrium. (ii) An increase in the export tax rate on the rural good does not affect the incentive to resolve urban institutional failure.

From result $(i)$, under free trade $(\tau=0)$, an increase in the export tax rate strengthens the incentive for rural institutional change to a perfect private property system when the relative share of labor $\left(w_{R} L_{R} / R\left(L_{R}^{*}\right)\right)$ in the rural sector is larger or the rate of increase (decrease) in the gross urban unemployment rate (rural wage rate) is higher at the initial equilibrium. ${ }^{17}$

\subsection{Institutional changes under an import tariff on the urban manufactured good}

Next, we consider how an import tariff rate on the urban manufactured good may induce urban institutional change and affect the incentive for rural institutional change. We will first show the comparative-static results of the ad-valorem tariff rate $t \geq 0$ (see the online appendix for the derivation). ${ }^{18}$

Proposition 4. An increase in the import tariff rate on the urban manufactured good always: (i) decreases both the rural population $L_{R}^{*}$ and the rate of urban unemployment $\mu^{*}$, (ii) increases the rural income per capita $w^{*}$, and (iii) may either increase or decrease rural resource good production $R^{*}$ in the steady state.

Result $(i)$ implies that the import tariff on the urban manufactured good can make a mitigation of rural resource overuse and a reduction in urban unemployment compatible.

We now discuss the possible resolution of urban institutional failure. An increase in $t$ or in the capital stock or productivity in urban manufacturing shifts the value of marginal product $p F^{\prime}\left(L_{M}\right)$ upward in figure 4 (the curves and points after the tariff increase are shown with a tilde). With a sufficiently large shift, the equilibrium wage at $\tilde{H}$ will exceed $w_{M}$, that is, the demand for manufacturing labor is so large that the urban wage rate exceeds the minimum wage rate $w_{M}$ in equilibrium. Therefore, the import tariff could resolve the urban institutional failure.

\footnotetext{
${ }^{17} \mathrm{~A}$ rapid increase in $\lambda$ is associated with a rapid decrease in the rural wage rate because $w_{R}=w_{M} / \lambda$.

${ }^{18}$ In section 2 , we used $t$ as a time variable. Here, we focus on the steady state and use $t$ to represent an import tariff rate.
} 


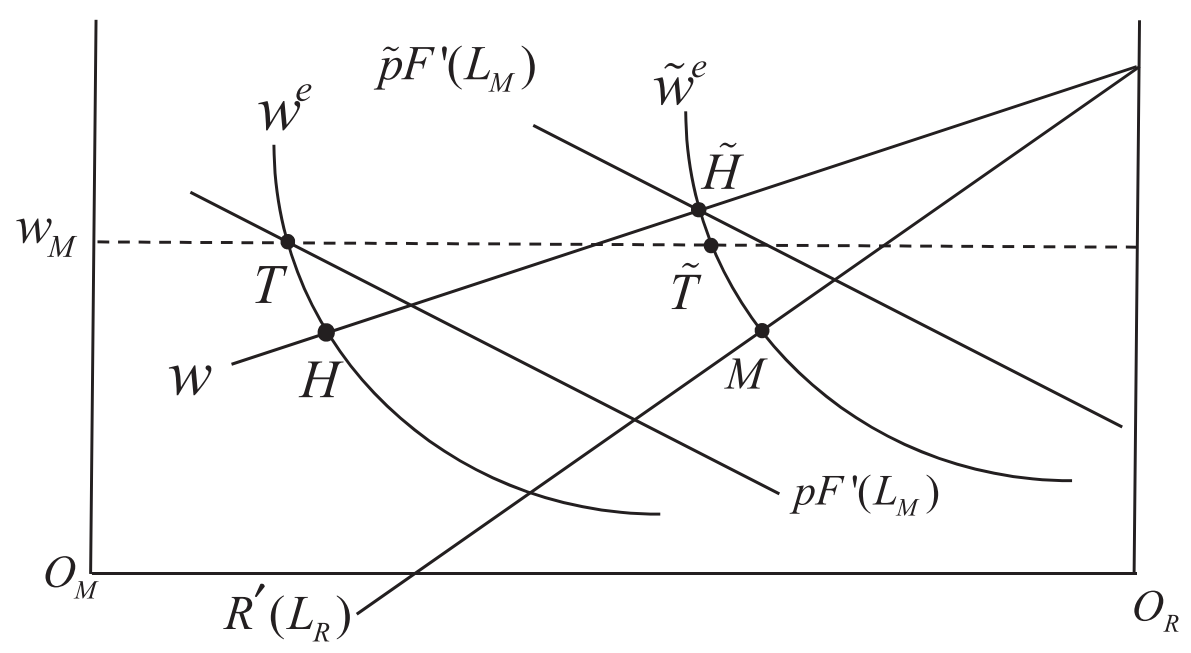

Figure 4. Resolution of urban institutional failure with open access rural resources.

Another finding of our paper is that the urban institutional failure will be resolved earlier when the rural resource is subject to open access than when it is private property. If the rural resources were private property, then rural labor demand would be given by the $R^{\prime}\left(L_{R}\right)$ curve in figure 4 . Then, the $H T$ equilibrium would still exist at point $M$, while urban institutional failure is resolved at point $\tilde{H}$ under open access rural resource.

Finally, we investigate whether rural institutional change from open access to a perfect private property system may occur through an increase in the tariff rate on the urban good. Consider the same hypothetical situation as in section 5.1 in which rural firms own the resource stock, except that there is no export tax. Then, the first-order condition for rural firms' profit maximization would be $w_{R}=R^{\prime}\left(L_{R}^{*}\right)$. By substituting $L_{R}^{*}$, we obtain the maximum sustainable rent as $\pi^{*}=R\left(L_{R}^{*}\right)-w_{R} L_{R}^{*}$. With $w_{R}=$ $w_{M} /(1+\mu)$, the change in $\pi^{*}$ due to an increase in the tariff rate is $\left(d \pi^{*} / d t\right)=$ $\left[R^{\prime}\left(L_{R}^{*}\right)-w_{R}\right]\left(d L_{R}^{*} / d t\right)+\left(w_{M} /\left(1+\mu^{*}\right)^{2}\right)\left(d \mu^{*} / d t\right)$. We find from $w_{R}=R^{\prime}\left(L_{R}^{*}\right)$ and $\left(d \mu^{*} / d t\right)<0$ that the maximum sustainable rent decreases:

$$
\frac{d \pi^{*}}{d t}=\frac{w_{M}}{\left(1+\mu^{*}\right)^{2}} \frac{d \mu^{*}}{d t}<0 .
$$

The results regarding endogenous institutional change can be summarized as follows:

Proposition 5. (i) An increase in the import tariff rate or in the capital stock or productivity of the urban manufacturing sector could resolve the urban institutional failure. (ii) Urban institutional failure is resolved earlier when the rural resource is subject to open access than when it is under a perfect private property system. (iii) An increase in the tariff rate on the urban manufactured good necessarily weakens the incentive for rural institutional change away from open access to a perfect private property system.

Proposition 5 may have important implications for small open developing countries that are highly dependent on open access natural resources. The introduction of an import tariff on the urban manufactured good will improve welfare because it reduces the 
rate of urban unemployment and rural resource overuse due to the gap between the average and marginal products of rural labor. ${ }^{19}$ While the governments of those countries will have an incentive to introduce import restrictions to protect the urban manufacturing sector, this industrialization policy tends to hinder the rural institutional change to a perfect private property system.

\section{Concluding remarks}

This paper has investigated how urban poverty reduction and rural resource preservation can be simultaneously achieved in a small open dual economy with urban wage rigidity and open access rural resources. First, an increase in the export tax rate on the rural resource good reduces rural resource overuse but necessarily increases the rate and level of urban unemployment, not only in the short run (when the rural resource stock is fixed) but also in the long run (when rural resource dynamics are considered). Because lower rural population increases the steady-state resource stock, a higher export tax may either increase or decrease rural output, GDP, and welfare in the steady state. The introduction of timber export regulations in some Southeast Asian countries from the 1970s to the beginning of the 1990s must have been welfare-improving because the timber production could be interpreted as exceeding the maximum sustainable yield, as suggested by the declining forest cover in the region. In the late 1990s when tropical forests were recovering, the governments of those countries reduced or abolished the export taxes and restrictions. Then, the distortion in the domestic prices of timber and the associated wood products would have been corrected. Because this effect tended to dominate the welfare-deteriorating effect of lower GDP, these policy changes must have been welfare-improving.

Second, the first-best policy, which makes the dual goals compatible, is a combination of an urban wage subsidy with a rural income subsidy at a lower rate. The first-best rural policy is a tax (instead of a subsidy) if the domestic price of the urban manufactured good is sufficiently high. Third, when institutions can change endogenously, an increase in the export tax on the resource good can induce rural institutional change away from open access, but tariff protection of urban manufacturing hinders such rural institutional change.

Our analysis could be extended in several directions. First, we can add agriculture in the rural sector. While labor reallocation from direct resource use to agriculture may alleviate resource overuse, land conversion for agriculture may accelerate resource overuse (e.g., deforestation). ${ }^{20}$ Second, we can incorporate capital in urban and rural sectors, investigating the effects of its intersectoral movement and endogenous investment. Third, rural resources could exert environmental externalities. Studies in these directions may result in richer findings and thus deeper insights on the compatibility between poverty reduction and environmental resource management in modern developing countries.

Supplementary material. The supplementary material for this article can be found at https://doi.org/10. 1017/S1355770X21000334.

\footnotetext{
${ }^{19}$ We provide rigorous proof of the welfare effects of the import tariff on the urban manufactured good in the online appendix.

${ }^{20}$ Jinji (2006) studies how international trade influences deforestation when the resource's carrying capacity is endogenous.
} 
Acknowledgements. We appreciate the discussions with Kenzo Abe, Scott Barrett, and Keisaku Higashida, and the comments from James Brander, Ngo Van Long, Kazuo Nishimura, Jota Ishikawa, Taiji Furusawa and Naoto Jinji regarding the previous version of this paper.

Financial support. Daitoh is grateful for the financial support from JSPS KAKENHI Grant Numbers JP16K03654 and JP24530241 (Grant-in-Aid for Scientific Research(C)) and Keio Gijyuku Academic Development Funds $(2013,2018)$.

\section{References}

Abe K and Saito M (2016) Environmental protection in the presence of unemployment and common resources. Review of Development Economics 20, 176-188.

Aide TM and Grau HR (2004) Globalization, migration, and Latin American ecosystems. Science (New York, N.Y.) 305, 1915-1916.

Barbier EB (2005) Natural Resources and Economic Development. New York: Cambridge University Press.

Barma NH, Kaiser K, Le TM and Vinuela L (2012) Rents to Riches? The Political Economy of Natural Resource-led Development. Washington, DC: World Bank.

Beladi H and Chao CC (2006) Environmental policy, comparative advantage, and welfare for a developing country. Environment and Development Economics 11, 559-568.

Bhagwati JN and Srinivasan TN (1974) On reanalyzing the Harris-Todaro model: policy rankings in the case of sector-specific sticky wages. American Economic Review 64, 502-508.

Brander JA and Taylor MS (1997) International trade and open-access renewable resources: the small open economy case. Canadian Journal of Economics 30, 526-552.

Brander JA and Taylor MS (1998) Open access renewable resources: trade and trade policy in a two-country model. Journal of International Economics 44, 181-209.

Bulte EH and Barbier EB (2005) Trade and renewable resources in a second best world: an overview. Environmental and Resource Economics 30, 423-463.

Chao CC, Kerkvliet JR and Yu ESH (2000) Environmental preservation, sectoral unemployment, and trade in resources. Review of Development Economics 4, 39-50.

Chichilnisky G (1994) North-south trade and the global environment. American Economic Review 84, 851-874.

Copeland BR (2005) Policy endogeneity and the effects of trade on the environment. Agricultural and Resource Economics Review 34, 1-15.

Copeland BR and Taylor MS (2009) Trade, tragedy, and the commons. American Economic Review 99, 725-749.

Corden MW and Findlay R (1975) Unemployment, intersectoral capital mobility and development policy. Economica 42, 59-78.

Daitoh I (2003) Environmental protection and urban unemployment: environmental policy reform in a polluted dualistic economy. Review of Development Economics 7, 496-509.

Daitoh I (2008) Environmental protection and trade liberalization in a small open dual economy. Review of Development Economics 12, 728-736.

Daitoh I and Omote M (2011) The optimal environmental tax and urban unemployment in an open economy. Review of Development Economics 15, 168-179.

Dean JM and Gangopadhyay S (1997) Export bans, environmental protection, and unemployment. Review of Development Economics 1, 324-336.

de Janvry A and Sadoulet E (2016) Development Economics: Theory and Practice. New York: Routledge.

de Meza D and Gould JR (1992) The social efficiency of private decisions to enforce property rights. Journal of Political Economy 100, 561-580.

Fischer C (2010) Does trade help or hinder the conservation of natural resources? Review of Environmental Economics and Policy 4, 103-121.

Grau HR and Aide TM (2008) Globalization and land-use transitions in Latin America. Ecology and Society $13,16$.

Harris JR and Todaro MP (1970) Migration, unemployment and development: a two-sector analysis. American Economic Review 60, 126-142.

Izquierdo AE, Grau HR and Aide TM (2011) Implications of rural-urban migration for conservation of the atlantic forest and urban growth in Misiones, Argentina (1970-2030). AMBIO 40, 298-309. 
Jinji N (2006) International trade and terrestrial open-access renewable resources in a small open economy. Canadian Journal of Economics 39, 790-808.

Margolis M and Shogren JF (2009) Endogenous enclosure in north-south trade. Canadian Journal of Economics 42, 866-881.

Noack F, Riekhof MC and Quaas M (2018) Development in a dual economy: the importance of resourceuse regulation. Journal of the Association of Environmental and Resource Economists 5, 233-263.

Rapanos VT (2007) Environmental taxation in a dualistic economy. Environment and Development Economics 12, 73-89.

Simms A and Reid H (2006) Up in smoke? Latin America and the Caribbean: the threat from climate change to the environment and human development. Oxfam Policy and Practice: Climate Change and Resilience $2,1-48$.

Tachibana S (2000) Forest exploitations and timber export restrictions in Southeast Asian countries. Reginal Policy Research 3, 49-71, (in Japanese).

Todaro MP and Smith SC (2015) Economic Development, 12th Edn., London: Pearson.

Tsakiris N, Hatzipanayotou P and Michael MS (2008) Pollution, capital mobility and tax policies with unemployment. Review of Development Economics 12, 223-236.

Wang L (1990) Unemployment and the backward incidence of pollution control. Journal of Environmental Economics and Management 18, 292-298.

World Trade Organization (2010) World Trade Report 2010: Trade in natural resources. Available at https://www.wto.org/english/res_e/publications_e/wtr10_e.htm.

Cite this article: Daitoh I, Tarui N (2022). Open access renewable resources, urban unemployment, and the resolution of dual institutional failures. Environment and Development Economics 27, 316-332. https://doi. org/10.1017/S1355770X21000334 